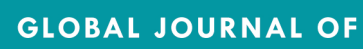 \\ Community Psychology Practice
}

PROMOTING COMMUNITY PRACTICE FOR SOCIAL BENEFIT

\author{
Creating Deep Democracy through Peer Wellness Services \\ Meghan Caughey \\ Cascadia Behavioral Healthcare
}

\section{Author Notes:}

Meghan Caughey, MA, MFA, is Senior Director of Peer and Wellness Services for Cascadia Behavioral Healthcare, Portland, Oregon. Meghan.caughey@cascadiabhc.org

Keywords: Peer wellness, peer support, deep democracy, recovery, mindfulness practice

Recommended Citation: Caughey, M. (2014). Creating Deep Democracy through Peer Wellness Services. Global Journal of Community Psychology Practice, 5(1), 1-7. Retrieved Day/Month/Year, from (http://www.gjcpp.org/). 


\title{
Creating Deep Democracy through Peer Wellness Services
}

\begin{abstract}
As healthcare reform transforms systems of care, there is a compelling necessity for systems to value the contributions of persons with lived experience of psychiatric diagnosis. The concept of deep democracy, of non-violence in action, is consistent with persons who have lived experience leading healthcare reform and helping transform coercion and oppression into health and wellbeing. Consistent with deep democracy and the creation of a "culture of wellness" for persons with mental challenges, a Portland, Oregon community behavioral healthcare program utilizes Peer Wellness Specialists and initiates a new model of integrated care that values whole health. The Cascadia Peer Wellness Program utilizes the unique and powerful resource of persons with lived experience of psychiatric diagnosis by training and employing Peer Wellness Specialists to partner with clinicians and other healthcare team members in order to help those they serve find their way to recovery.
\end{abstract}

Keywords: Peer wellness, peer support, deep democracy, recovery, mindfulness practice

I clearly remember how deeply shaken I was when the 2006 report from the National Association of State Mental Health Program Directors came out saying that people with serious mental illness who are treated in the public system die an average of 25 years earlier than the general population (Parks, Svendsen, Singer, \& Foti, 2006).

I was diagnosed with schizophrenia when I was nineteen. When this report came out I had finally reached a place in my personal recovery that allowed me to work as a peer mentor in a community mental health program. I realized that during the four months I had been working at the program, four of my peers who had received services there had died prematurely. This felt very personal - like a body blow — and my response was to vow I would dedicate my work to ending premature mortality and improving the quality of life for those who have psychiatric disabilities. It is not enough for those of us with disabilities to do the hard work of creating our recovery and then to die; it is our equal right to live well and enjoy longevity. This basic right is accomplished within the context of an environment, which is imbued by "deep democracy". Deep democracy is founded upon a social agreement for community members to adhere to non-violence in language and behavior. I became convinced of the necessity of this as a way to escape my dismal pattern of violence and hospitalization.

During this time, I acted out self-harm and found myself hospitalized against my will. My behavior was repeatedly controlled by mechanical and chemical restraints. I did not know that I had any power or responsibility to address my difficult emotions except by physically struggling. Likewise, the hospital staff reinforced my beliefs that I had no control over my actions. This disturbing scene was to be repeated many times over many hospitalizations. Finally, I reached a point where I saw that I would either have to do something different or live without my freedom. I had started meditating years before and finally became convinced that acting out violently was not consistent with my meditative experience. I was not sure if change was truly possible, but the alternative was no longer workable. I was no longer willing to live my life within the walls of an institution. My intention became to create a different life for myself, and I soon started seeing opportunities that became expressions of a nascent sense of empowerment and self-determination. A new locus of control started growing within me. This change was built upon a new choice to find non-violent ways to express myself; to express the seemingly bottomless sense of pain that had been with me for much of my life by making art rather than acting out. This then became the beginning of my recovery. I sought reinforcement for my changes within a Buddhist community that supported my meditation practice.

Here, non-violence was the norm, and I eventually grew to regard it as my own.

As my recovery strengthened, I started to look for opportunities to express myself through peer work where I could serve other persons who had lived experience of their own mental health struggles. Through my work as a "peer mentor"ein a community mental health program, I sought to spread the idea that individuals have the ability to choose non-violence, even in the middle of our hardest struggles. I relied upon a number of tools, including the practice of mindfulness and the expression of feelings through my paintings and drawings. Persons who have serious 
mental health challenges need the example of others who may still struggle in their lives with their own mental health, but who are successful in creating their own fulfilling and gratifying lives. I created the Peer Wellness Program so that my own journey of expressing my inherent wholeness might serve as a source of hope for my peers.

\section{Deep Democracy}

My own journey towards nonviolence set the stage for discovering the concept of "deep democracy" (Gastil,1993). The environment where this deep democracy flourishes is predicated on the social agreement of all members to adhere to non-violent communications and behavior and is counter to coercion and oppression. There must be healthy alternatives to violent speech and other behaviors, even including violence towards our planet such as demonstrated by our slowness to mitigate global warming. Deep democracy, then, is not a politic, but rather a far- reaching belief system that is predicated upon equality, self-responsibility and mutuality. (Bloom \& Farragher, 2013) The practice of deep democracy is multidimensional and is expressed throughout the multiple levels of analysis, including individuals, environments, organizations, and societies. The basic attitude of deep democracy is kindness and respect.

\section{The Wellness Model}

The Wellness Model sets the tone for the creation of deep democracy in behavioral health care. (Caughey, 2011). It is a statement of belief of which the following tenets form a strengths-based platform of hope. Upon this basis of hope, deep democracy may be founded.

1) It is a human right for persons with lived experience of psychiatric diagnosis to recover and be well, and expect to live a gratifying life without suffering preventable disease and premature death.

Even today, it is rather revolutionary to believe that one can recover from serious psychiatric disability. Although the talk of recovery is widespread among mental health providers, the genuine belief that it is possible for the most complex and "disturbed" individuals is sometimes very challenging, even for the most "recovery oriented"clinician.

2) We have the ability to make choices that support our wellbeing, safety, and health.

In order for those of us with mental illness to change in a way for which we can take ownership of our lives, we must be convinced that there are, in fact, choices for us and that the act of choosing belongs to us, not to our clinicians. Further, we must have a basic sense of selfefficacy: the belief that we can impact both our own situation and also have some ability to shape our environment.

\section{3) It is our right to have the support of a holistic health system in pursuing our optimum health.}

Systems that are splintered into the rubric of behavioral health and physical health try to tear us into pieces, rather than support our healing. It is a human right to be treated such that individuals are recognized at a level of personhood, at which we are all whole instead of a jumbled collection of fragments. We are inherently whole at the deepest level of our being.

When individuals engage a system from a position of intrinsic wholeness, the template for personal health is reinforced and made manifest. Health systems that are grounded in a holistic perspective contribute to the well-being of both persons served as well as providers. Also, just as we aspire for personal health in the holistic sense, we need to aspire for health of the systems that we inhabit.

\section{4) Systems that decree that we are "broken"rand need to be "fixed" by clinicians are oppressive and contribute to suffering and sickness.}

The belief that we are broken is a misperception in which the medical model has invested significant resources. We are not infected with the "germ" of mental illness. If those of us who have mental health issues only believe that the path for our healing lies in the hands of our health providers, then we will never claim the power necessary for our healing that is so necessary for us to heal our systems. We do not need to be fixed; we are not broken.

\section{5) If we try to push people into wellness and} recovery, we are contributing to oppression.

It is generally understood that people do not change significantly until they are ready to change, which usually requires an environment that supports belief in our healing. However, we must ask: how much of mental health treatment is predicated on the belief that if providers just push hard enough, then their efforts will be rewarded by a desired behavior? In fact, this situation is a sort of oxymoron: clinicians sometimes push us towards the goal, but at the same time, they are doubtful that we can ever make it there. If systems are focused on achieving their own outcomes without first asking individuals what they themselves desire, then the stubborn weight of those systems' expectations bear down and stifle individuals' own creative energy, which is also necessary in order for healing to be possible.

6) If mental health workers heal alongside the persons with whom they work and create healing relationships, then an opening for healthful lifestyle choices can be investigated and, in time, embraced. 
Clinicians and consumers need to engage in a mutual fashion. Hierarchies do not promote healing; they disempower the persons nearest the bottom while removing those at the top from honest reality. Healing must be done between equals. As long as trauma is the leading force in many of our lives, we are hardly free to use our energy for being curious about what life would be like were we aware of our own beauty. However, in the context of safety and mutual exploration, trauma may be exposed much as the Wizard of Oz was exposed as a small, deflated man behind the great curtain.

\section{Characteristics of Deep Democracy}

A healing environment and system (Bloom and Farrager, 2013) is characterized by a commitment to:

Non-violence. There is an agreement among all members that communication and interpersonal relating will be without violence. This means nonviolence of words and actions, either manifest or implied.

Equality. The playing field is level, and everyone has the expectation that they will be treated with respect and meaningful regard.

Autonomy. Individuals have the power to determine what path is right for them.

Open communication. There is an agreement to engage one another and to do so with honesty

Deep listening between all persons within the system. Every member is encouraged to use his or her voice, and there is equality in the importance ascribed to each.

These concepts of deep democracy necessitate both the enlisting of and the listening to persons with lived experience of mental health challenges. Deep democracy replaces systemic hierarchy with valuing diverse cognitive and emotional styles. This makes it possible to create new possibilities of what is possible for persons who are coping with their personal mental health challenges. Consistent with behaving nonviolently, health providers do not define their roles as guarding control of individuals receiving services. Controlling another's behavior is oppressive, but creating an environment where all members are respected and empowered to express their personal and collective strength reframes the social roles of all involved. At the same time, regarding members from a whole health perspective rather than as limited to behavioral health helps create the possibility of deeper change. At present it is all too common for behavioral evaluation and treatment to take precedence over a way of relating that addresses the interconnectedness and synergy of all members of the community.
If health reform tries only to remake the old ways of doing things, if it binds those of us who have psychiatric disabilities to the same old worn out definitions, it will surely fail, since the old ways are designed to uphold rigid inertia and illness - not transformation and health. We need to drive a health reform that is truly about creating health and not just a ruse for perpetuating sickness.

\section{Peer Wellness Specialists Program}

The effectiveness of peer support in mental health settings has been well documented (Daniels, Grant, Filson, Powell, Fricks, \& Goodale, 2010). A form of peer support: the Peer Wellness Specialist Program was originally created by the author of this paper in 2006 in Benton County, Oregon. In 2011, this author brought the training and program design to Cascadia Behavioral Healthcare in Portland Oregon. Now the Cascadia Peer Wellness Program is a robust example of how Peer Wellness Specialists (PWS) are creating a movement that has the ability to transform systems so that they are characterized by health equity and social justice. It is an exemplar model of how healthcare services are informed by deep democracy in the climate of healthcare reform.

The journey of this movement begins with persons who self-identify as persons who have lived experience of a psychiatric diagnosis. Peer Wellness Specialists (PWS) do not usually call themselves "the mentally ill," although this is the pejorative nomenclature that society reserves for them. Instead, their self -conscious language choices reflect determination to use every opportunity to remake the status quo.

The CPWP operates within the system of a community mental health organization and, most importantly, within systems that integrate behavioral and physical care. PWS act from the position of believing they can effectively change the system from within. From the first day of the Peer Wellness Specialist training, trainees relate to themselves and to one another not on the basis of their diagnoses, or of their woundedness, but from their strengths. They focus on how their personal attributes contribute to the training being a success. The 120-hour training is designed to be transformational. When trainees have reached the point of completion at the end of 18 weeks, they are more recovered than when they began.

The concept of placing persons with lived experience at the forefront of healthcare reform acknowledges that this health disparity population is an outstanding resource for great energy and change. In the old order, these persons with lived experience of psychiatric diagnosis were typically regarded as liabilities and as vacuous consumers of resources. This dynamic change 
is created when individuals are valued for all aspects of their personal struggles and triumphs. The PWS trainees set personal goals for their own wellness and support one another in reaching these goals. There is a sharp recognition of how the medical model sometimes reinforces hierarchy and inequity for the persons being served; and PWS commit to turning this around.

By self-disclosing their own successes in confronting mental health issues and diagnosis, PWS are able to relate in a way that serves as both a role model and as a source for hope. They do not infer that healing will come from sources outside themselves; rather, they strongly believe that people have within them the power and deep knowledge of their own path to wellness. Furthermore, PWS demonstrate how personal strengthsbased definitions can replace the pejorative, diseasebased diagnoses. Generally, healthcare reform aims to be "person-centered." Peer wellness specialists go on step further and work to create a system that is "persondriven." Instead of service providers simply encircling the people they serve, PWS support the active empowerment of individuals to determine and pursue what they need. The hub drives the wheel. This is to say that there is a great deal of collaboration and support in this self-driven model. It fundamentally shifts the loci of control to the persons receiving services.

PWS are not only allies to the individuals whom they serve, but they are also certain allies for the clinicians and other members of the healthcare team. Each person's role on the team is unique and valuable to the others. When PWS first begin working within a program, side by side with clinicians, there may be initial confusion and lack of understanding of each other's roles. However, after an adjustment phase, where all concerned are learning each other's style of working, both the PWS and clinical staff come to mutual appreciation. The clinicians find, sometimes to their surprise, that PWS have a unique and constructive frame of reference that has arisen from their own experiences and which can be the source of powerful supportive and therapeutic interventions.

The inspiring journey that the PWS trainees make towards their becoming full-fledged PWS expresses the magnitude of the power inherent in belief and hope in the healing process. Often, trainees find that they have exceeded their own expectations of themselves by overcoming years of maladaptive thought and behavior and breaking through to the creation of their own freedom. PWS, who work in mutuality with their peers in treatment, provide a sense of hope that non-peer providers cannot replicate.

Intentional Wellness and the Role of Mindfulness Practice
Wellness arises out of personal and system intention. This implies that wellness does not simply happen; it is created. This occurs on a personal level by purposeful individuals; and at the systems level, it is created by the deliberate inter-connected actions of the system's members. In order to intentionally create wellness, the practice of mindfulness may be employed. The practice of mindfulness at a personal level helps to clear away the "mind clutter"i(i.e., traumatic memories) so that a ground of wellness may arise. The value and communal practice of mindfulness at an organizational level reinforces the personal and collective intention towards wellness of community members and of greater systems. PWS work with mindfulness to address their own issues of trauma. By strongly focusing on the present moment (having the "mind full" of the present), PWS are able to move beyond the traumas of the past and fears of the future. PWS have also brought the practice of mindfulness into the larger system by commencing meetings and groups with mindfulness practice. Also, during meetings and classes, a "mindfulness bell" may be rung at random times signaling the participants to briefly cease their discourse and take a few moments to focus on their breathing and to center themselves. From the beginning of their training, PWS practice mindfulness and are encouraged to develop a personal expression of its use. By carrying mindfulness to their own personal lives, they are able to utilize the practice creatively in service when supporting their peers. When endeavoring to assist anxious or panicking peers to calm themselves, the PWS may use guided mindfulness techniques. Another example of the use of mindfulness is found during the wellness support group known as the L.O.T.U.S. Group (Lifestyles Overcoming Trouble Utilizing Support). Here, the PWS facilitators have combined the practice of mindfulness with the practice of monitoring participants' blood pressures.

Cardiovascular disease and chronic pain are very common problems that the practice of mindfulness can help to alleviate (Kabat-Zinn, 1982).

At the start of the group, participants are taught by the PWS to take their own blood pressure and then are led in a mindfulness exercise. After twenty minutes of focusing on the breath and using techniques that foster attention to the here and now, the participants again take their blood pressures. Often the scores are improved at the second reading. Participants are excited to see in real time how they are able to create their own heart health. The PWS work from a position of mutuality and cultivate health literacy, empowerment and self-efficacy among all members of the group. This hands-on demonstration is preventive and healing both in physical and psychological domains. It is an example of how to impact the inequity and disempowerment that 
persons with mental health issues face as a health disparity population. The fact that this group is peerfacilitated helps to underscore that wellness is a process that is open to all to engage in, regardless of the starting point.

\section{The PWS Model of Care and Healing}

The model of the PWS workforce exemplifies how behavioral health and primary care can be integrated at the level of peer delivered services. PWS are part of primary care health teams that focus on assisting persons who have complex issues and who rely on the emergency department and inpatient services for their care. PWS do not psychopathologize others, but normalize complex situations and create the expectation that individuals can develop their own skills for selfmanaging their health issues.

The Peer Wellness Program is an alternative to oppressive systems of "care"aas it creates an environment that is conducive to deep democracy where everyone has an opportunity to express themselves and where the group listens to and values all members. One person who was working with a PWS stated the supportive experience as follows: "I like working with you because you will always listen to me when no one else will."

\section{Creating a Peer Wellness Program and Lessons Learned}

It is important to design peer workforces in an overall systems framework. Adding peer-delivered service workers does not in and of itself transform a system. The inclusion of PWS is a starting point, but there must be a genuine move from coercion and oppression of persons who have psychiatric diagnoses to a latent and manifest respect of all persons'aworthiness. In terms of workforce design, it does not work as well to simply hire a single "peer "in order to create effective peer services. The whole community must be addressed and PWS must not be isolated from other PWS in other parts of the organization. Opportunities for mutual PWS support must be created. We prefer to place at least two or more PWS in each program, even if they do not work the same hours. Also, it is important that PWS are trained by persons who have lived experience and are themselves PWS. The leadership of PWS must be conducted by peers. More than two hundred twenty-five individuals have been trained as PWS in Oregon. Cascadia Behavioral Healthcare currently employs more than twenty-five PWS who are working with well over two hundred peers engaged in services. The goal is to have a significant percentage of the entire community behavioral health organization's workforce be made up of persons who have lived experience of psychiatric diagnosis. The whole health team and treatment community must be involved and evolved if the PWS are to succeed. Commitment to success must be expressed at all levels of organizational leadership.

\section{Conclusion}

Although we seem to be in the early stages of healthcare reform, there is a critical mass that has risen to make real the hope for a socially just system where the activity of creation is the right and practice of all members. The building of deep democracy promises both health for individuals, as well as more healthy and health-supporting institutions. Also, it is consistent with individuals engaged in social and environmental change. At Cascadia the use of PWS has increased the respect for persons receiving services. In Oregon the valuing of persons with "lived experience" is growing. We must create the world in an intentional way that pushes no one out, but where we are all at home and our individual lives are valued by the whole. Our current design of reform and movement towards development of deep democracy is just the beginning. We must constantly design a future where there is true inclusion and justice. In fact, we really must do this now. We cannot afford to push it off into tomorrowtoo much is at stake. Peer wellness specialists and persons with lived experience of mental health challenges are the advance guard. As the canaries rise up from the coalmine (perhaps now transformed into a goldmine) they must be free to fly and fill the trees with their song-although they are not really canaries; their truest nature is that of the phoenix.

\section{References}

Bloom, S. L., \& Farragher, B. (2013). Restoring sanctuary: A new operating system for traumainformed systems of care. Oxford University Press.

Caughey, M. (2011). Personal accounts: Making art, exploring madness. Psychiatric Services, 62(2), 126-127.

Daniels, A., Grant, E., Filson, B., Powell, I., Fricks, L., \& Goodale, L. (2010). Pillars of peer support: Transforming mental health systems of care through peer support services. Rockville, MD: Substance Abuse and Mental Health Services Administration.

Gastil, J. (1993). Democracy in small groups: Participation, decision making and communication. Philadelphia, PA: New Society.

Kabat-Zinn, J. (1982). An outpatient program in behavioral medicine for chronic pain patients based on the practice of mindfulness meditation: Theoretical considerations and preliminary results. General Hospital Psychiatry, 4(1), 33-47. 
Kabat-Zinn, J. (1993). Psychosocial factors in coronary heart disease: Their importance and management. In I.S. Okene and J. Okene (Eds.), Prevention of Coronary Heart Disease (299-333). Boston: Little Brown.
Parks, J., Svendsen, D., Singer, P., Foti, M.E., (Eds). (2006). Morbidity and mortality in peoplewith serious mental illness (13th technical report). Alexandria, VA: National Association of State Mental Health Program Directors Medical Directors Council. 